\title{
Vulnerability as a Precondition for Resistance and Agency: Young Women in a Regional Community
}

\author{
Kitty te Riele ${ }^{1} \mathbb{D} \cdot$ Becky Shelley $^{1}$
}

Received: 23 December 2020 / Revised: 20 July 2021 / Accepted: 26 July 2021 /

Published online: 19 August 2021

(C) The Author(s), under exclusive licence to Springer Nature Singapore Pte Ltd. 2021

\begin{abstract}
Any terms that designate certain groups of young people as more in need of support or intervention are likely to be contested. Identification of some young people as vulnerable can lead to tensions between rights and blame and between support and stigma. This paper draws on scholarship that posits vulnerability as emerging as part of specific social and historical conditions, and as a precondition for resistance and agency. We use publicly available data and information to focus on a community in a regional area in Australia and on a specific initiative for young women in that community. In relation to conditions, we detail salient characteristics of the region: north-west Tasmania. We show how structures of social, economic, and cultural inequalities provide the context for the vulnerability of young women living here. In this community, as elsewhere in Australia and globally, national economic reforms have accentuated social and economic disadvantage. We then move on to examine a participatory arts initiative, Project $\mathrm{O}$, that works with young women in this region. We outline how Project $\mathrm{O}$ is an example of a practical way to harness the potential of vulnerability as a starting point for both resistance and agency, through positive connections with place and identity; by enabling young women to act on their aspirations; and by developing capabilities and providing recognition.
\end{abstract}

Keywords Vulnerability $\cdot$ Resistance $\cdot$ Agency $\cdot$ Regionality $\cdot$ Participatory arts

\section{Introduction: Vulnerability}

"I am going to move mountains"

Song title by Kaitlyn

Kitty te Riele

kitty.teriele@utas.edu.au

1 University of Tasmania, Peter Underwood Centre, Hobart, TAS, Australia 
Any terms that designate certain groups of young people as more in need of support or intervention are likely to be contested. Over the past few decades, different terms have gained currency, such as 'disadvantaged' youth, 'youth-at-risk', 'marginalised' youth, 'disenfranchised' youth, and 'vulnerable' youth. The extent to which these terms have deficit connotations varies. Vulnerability-the term used in this special issue-evokes a sense of meritorious neediness: a young person does not choose to be vulnerable and thus cannot be personally blamed for needing support. Of course, distinctions between the 'deserving' and 'undeserving' poor have long (and justly) been critiqued in sociological scholarship (Katz 2013). Moreover, vulnerable people may be seen as somehow passive victims, subject to 'paternalistic forms of power' (Butler et al. 2016: 1). Arguing against this view, Butler et al. (2016) suggest that vulnerability is more usefully conceived of as a precondition for resistance and agency. They show how the concept of vulnerability in itself can be used to 'support any version of politics and has no special claim to supporting a politics on the Left, or a politics for feminism' (2016: 2). It is not inherently 'good' or 'bad'. In this paper, we appreciate the way Butler et al. navigate the different ways in which vulnerability has been conceptualised and applied and support their proposition:

if we argue instead that vulnerability emerges as part of social relations, even as a feature of social relations, then we make (a) a general claim according to which vulnerability ought to be understood as relational and social, and (b) a very specific claim according to which it always appears in the context of specific social and historical relations that call to be analyzed concretely. (2016: 4)

Importantly, whichever term is used, some kind of identification is involved of who is considered vulnerable (or disadvantaged). As outlined by Te Riele (2015), such identification and categorisation leads to two dilemmas.

First, when individual young people are identified as vulnerable, this can recognise their human right to equal participation in society. On the flipside, however, it may also lead to deficit perceptions, locating the causes or characteristics of vulnerability (such as 'truancy' from school or teen pregnancy) with the young person-ignoring the 'context of specific social and historical relations' Butler et al. (2016: 4) rightly point to. In this paper, we therefore both promote the human right of each individual person to lead the life they have reason to value (Sen 1999) and take a contextual perspective which draws attention to the ways in which experiences of vulnerability are linked to structural inequalities.

Secondly, in much social policy and research, vulnerability is related to characteristics at the level of a specific group. For example, in identifying 'who succeeds and who misses out' in education in Australia, Lamb et al. (2020) apply well-recognised categories including gender, parental education, geographic location, language background, and Indigenous status. Statistical analysis using such categories is an illustration of the concrete analysis of social relations called for by Butler et al. in the quote above. Identifying a group of young people as vulnerable may improve service delivery, by enabling 'limited resources to be targeted 
at those who need them most' (Te Riele 2015: 23) and ensuring services are relevant to specific groups. Such identification may also, however, lead to increased stigmatisation. As Butler (2016: 16) points out:

One clear dimension of our vulnerability has to do with our exposure to name-

calling and discursive categories in infancy and childhood, indeed, throughout the course of life.

Vulnerability is not abstract, neutral, or objective. It is relational and social (Butler et al. 2016), and it is therefore fruitful to examine vulnerability in relation to a specific context. We acknowledge that while belonging to a specific group (such as First Nations Australians, or low socio-economic background) does not make social and educational vulnerability inevitable, these contexts do make it more likely compared to more privileged life circumstances.

While people in regional communities would (rightfully) bristle at being characterised at a broad sweep as 'vulnerable', the 'specific social and historical relations' (Butler et al. 2016: 4) in Australia demonstrate a persistent educational inequity between regional and urban communities (Lamb et al. 2020). Despite such structural disadvantage, however, young people in regional communities have been shown to have high aspirations for the life they wish to live (see Hawkins 2014).

Recognising intersectionality as well as the potential compounding effect of such characteristics, the broad focus of this paper is on young women from a low socioeconomic, regional community in Australia who are involved in an initiative named Project $\mathrm{O}$. Project $\mathrm{O}$ aims to support young rural women to help prevent family violence and drive generational change. Project $\mathrm{O}$ has been piloted in a federally designated 'family violence hotspot' (see Medhora and Evershed 2015) of the north-west coast of Tasmania and subsequently being rolled out in three other regions in Australia: Cooma (New South Wales), Roebourne (Western Australia), and Canberra (Australian Capital Territory). ${ }^{1}$

Below, we detail salient characteristics and experiences of the community-the north-west of Tasmania-where possible in relation to the whole of Tasmania and/ or Australia. The analysis here draws on a wide range of publicly available sources, largely of a quantitative nature. These draw a picture of a community that can be considered relatively vulnerable on a wide range of markers. This picture highlights the 'specific social and historical relations' (Butler et al. 2016: 4) of the context in which the Project $\mathrm{O}$ participants live.

\section{Considering the Context}

lutruwita in palawa kani, the language of Tasmanian Aborigines, is the place name for Tasmania, an island state of Australia with a population of just over half a million people. Over $50 \%$ of its land is protected as state forest, national

\footnotetext{
1 https://www.bighart.org/projects/project-o/
} 
parks, or reserves with World Heritage status. As a small regional economy, the island has experienced social, economic, and environmental changes and with these have come resistance, acceptance, profit, and loss (Hardy and Ooi 2020). Forestry, mining, agriculture, and manufacturing industries have been the site of environmental debates as well as economic restructuring. Global demand for the resources Tasmania produces has fluctuated, and industry capacity to secure a social license has been influenced by environmental activism. Economist Saul Eslake (2020: 59) observes that:

Tasmania went into the recession of the early 1980s in unambiguously worse shape than the mainland: this recession took a heavy toll on the manufacturing industry, on which Tasmania was then significantly more reliant than Australia as a whole. Tasmania's economy was also adversely affected by the lengthy dispute over the proposed construction of the Gordon-below-Franklin dam... [After recessions during the 1980s, 1990s, and global financial crisis] the unemployment rate rose by more, to a higher level, and took longer to come down to its pre-recession level in Tasmania than it did on the mainland; and employment fell by more, and took longer to regain its pre-recession peak level, in Tasmania than it did on the mainland.

In Tasmania, as in other regional communities across Australia and globally, economic changes have accentuated economic marginalisation. Questions of social change and of how young people in rural communities are creatively making lives in less than ideal circumstances have been extensively explored in Australia(Cuervo and Wyn 2012; Wierenga 2009). As Cuervo and Wyn (2012: 29) point out: 'Rural restructuring and the consolidation of the different social and economic relations present significant implications for young people', in particular in relation to education and employment. In this section, we provide some broad-sweep data, based on what is available, but we agree that young people in rural areas are not 'a categorical and universal entity' (Cuervo and Wyn 2012: 36). Rather, this section paints the broader landscape in which the individual young women in Project $\mathrm{O}$ live.

There are pockets of persistent socio-economic and educational disadvantage across Australia-and the north-west of Tasmania is one such place. It sits on the periphery of the Australian economy and the margins of the global economy. This has contributed to young, working age people leaving the region. Although Tasmania overall is experiencing population growth, among local government areas on the north-west the population is in significant decline (Denny and Pisanu 2019: 10). It is a stark contrast to the past, when a large private sector employer utilised the island's natural timber resources to make paper.

Butler (2016: 21) posits 'the human body as a certain kind of dependency on infrastructure' in order to 'foreground the ways in which we are vulnerable to decimated or disappearing infrastructures, economic supports and predictable and well compensated labour'. In the context of the north-west coast of Tasmania, Barton (2015: 153) argues that deindustrialisation was part of an inevitable process of globalisation yet finds that blame for the closures was sheeted home to the people of the region, rather than being seen as a consequence of broader political and economic choices. 
Noting the limits to statistically derive understandings, it is evident that young people living in the north-west coast are likely to encounter structural disadvantage. Mirroring the broad pattern of the national figures, Tasmanians with lower income, employment, and education levels are less digitally included than on mainland Australia. Tasmania's Australian Digital Inclusion Index (ADII) score in 2020 is 59.6. This is 3.4 points below the national average (63.0) and positions Tasmania as the least digitally included of Australia's eight states and territories (Thomas et al 2020, p.41).

Other contextual characteristics relevant to our analysis include the region's school-to-work culture; a low tradition to pursue university studies; as well as highly gendered occupational aspirations and fields of work (Hawkins 2017). The highest level of secondary schooling completed within the Cradle Coast Region ${ }^{2}$ is lower than the Tasmanian and Australian averages (see Table 1). Noteworthy is that only just over a quarter of the population in the Cradle Coast has completed year 12 (the final year of senior secondary education), compared to over half across Australia.

The relative socio-economic disadvantage of the Cradle Coast compared to Tasmania, and of Tasmania compared to Australia, is similarly confirmed by indicators such as household income, occupation and qualifications (ABS 2016).

Tasmanians fare worse than the national average in all but seven of 23 indicators for all four stages of learning and development, and rank seventh or eighth (out of eight) in 12 of those: while of five 'lifelong learning indicators', Tasmania ranks last or second-last in all but one (Lamb et al. 2020). Unsurprisingly then, improving educational attainment has become regarded as a policy panacea with the power to improve Tasmanians' material living standards relative to those of other Australians (Denny et al. 2019). To improve educational outcomes in Tasmania, a combination of legislative and organisational reforms has been initiated. A key change within the Education Act (Tas 2016) is the requirement that students continue to participate in education and training until they complete year 12, attain a Certificate III (a vocational credential considered equivalent to Year 12), or they turn 17 years of age (18 years of age from 2020) (Department of Education Tasmania 2020).

Concomitant with changes to the legislation a diversification of options for students to complete years 11 and 12 . Formerly, government secondary schools finished at year 10, with years 11 and 12 offered though a small number of colleges. This required students in regional areas to travel often large distances simply to attend senior secondary school and may explain the relatively large proportion of Tasmanians for whom year 10 is the highest level of secondary schooling completed (see Table 1). Under the extension school reforms, between 2015 and 2020, 45 local schools have commenced offering years 11 and 12. For young people in small regional communities, it is a step towards increasing equity of access.

\footnotetext{
2 The Cradle Coast Region is located in north-western and western Tasmania. The Cradle Coast Region includes nine local government areas: Burnie City, Central Coast Council area, Circular Head Council area, Devonport City, Kentish Council area, King Island Council area, Latrobe Council area, WaratahWynyard Council area, and West Coast Council area.
} 
Of relevance to Project $\mathrm{O}$ is evidence that people at heightened risk of family violence include those who live in rural or remote regions and/or who experience socioeconomic disadvantage (AIHW 2019). There are issues relating specifically to geography and the practicalities of regional, rural, and remote life that affect the experience of family violence, such as isolation as well as social norms of self-reliance and privacy. In 2015 the Australian federal government announced a broad suite of measures to address domestic and family violence, including $\$ 15 \mathrm{~m}$ to establish hubs in locations considered 'hotspots'. Half of these were in regional communities, including one in north-west Tasmania (Medhora and Evershed 2015).

The fact that vulnerability is linked with structural disadvantage underlines the role that social conditions play in young people's lives on the north-west coast and elsewhere in Tasmania. However, to uncritically adopt a deficit stance undermines the dynamic and unpredictable realities 'specific social and historical relations' (Butler et al. 2016: 4) and risks ignoring the rich and unique potential contained within each young person's life.

\section{Focus, Approach, and Methods}

This paper is focused on young women involved in Project O, an initiative of Big hART, a not-for-profit organisation that was set up in north-west Tasmania in the mid-1990s. Participants in Project O are young women of secondary school age. Project $\mathrm{O}$ is being rolled out to additional locations, but the scope of this paper is limited to Tasmania, where the initiative began and where therefore most information is available. More detail about Big hART and Project $\mathrm{O}$ is provided in the next section.

Our research was conducted independently from Big hART-i.e. it was not a program evaluation. The project aim was to examine how the notion of vulnerability plays out in relation to the young women in Project O. We collated and analysed all information about Project $\mathrm{O}$ from the Big hART and Project $\mathrm{O}$ websites ${ }^{3}$ and from publications about Big hART. We included the official websites (see footnotes 1 and 3), examining all pages on those sites for relevant material, and also explored additional links. The materials include textual descriptions, videos, and photos created by Big hART; videos, blogs, and stories featuring and/or co-created by young women in the program; and media articles.

Sociological research based on online data has become common during the twenty-first century. While some have gone as far as proposing a new method of virtual ethnography based entirely on online fieldwork (Dominguez et al., 2007; Hine, 2000), we agree with Androutsopoulos (2008) that ethnographic online research would benefit from being supplemented with data collected directly with participants. Our purpose for using online materials for this paper is more modest: to provide close analysis of the notion of vulnerability in Project $\mathrm{O}$, with minimal impact on participants in the initiative. As Arora et al. (2016: 1904) argue: 'Websites offer

\footnotetext{
3 https://www.bighart.org and https://projecto.bighart.org
} 
Table 1 Highest level of secondary schooling completed (\% of population)

\begin{tabular}{lccc}
\hline Level of schooling & $\begin{array}{l}\text { Cradle Coast } \\
\text { Region }\end{array}$ & Tasmania & Australia \\
\hline Year 8 or below & 5.9 & 4.9 & 4.8 \\
Year 9 or equivalent & 10.5 & 8.2 & 5.6 \\
Year 10 or equivalent & 37.1 & 30.5 & 19.2 \\
Year 11 or equivalent & 9.5 & 8.7 & 9.1 \\
Year 12 or equivalent & 27.3 & 38.3 & 51.9 \\
Did not go to school & 0.3 & 0.4 & 0.9 \\
Not stated & 9.3 & 8.9 & 8.6 \\
Total persons aged 15+ & $\mathbf{1 0 0 . 0}$ & $\mathbf{1 0 0 . 0}$ & $\mathbf{1 0 0 . 0}$ \\
\hline
\end{tabular}

Source: Australian Bureau of Statistics (2016) [total persons, usual residence]

an unobtrusive data source for developing and analysing information about various types of social science phenomena'. Since websites are constructed by others, sensitivity is needed to the purposes of the representation by the website creators (Waters and Brooks 2015). The Project O materials appear largely to focus on a commitment to sharing stories; however, promotional elements are also evident. For clarity and transparency, we indicate the specific source for information we discuss in endnotes throughout this paper. This also serves to distinguish our data sources (i.e. from Big hART and Project O) from the references we draw on for analysis and interpretation.

Analysis initially examined all texts (including video transcript) that included any comment on the characteristics and experiences of the young women in Project $\mathrm{O}$. Treating Project $\mathrm{O}$ as a case study, we applied thematic analysis to this material, based on Creswell and Poth's (2017) approach. This involved two separate analysis: first in relation to the notions of resistance and agency from Butler et al. (2016) and then in relation to Big hART's focus on participants' being in the world, building participants' skills, and raising participants' status and recognition (Wright et al. 2016). Finally, we brought these two analyses together for the findings discussed in this paper.

In our findings, where possible, we foreground the experiences and views of specific participants. In particular we draw on two key'first person' narratives by Kaytlyn: a video (which was produced while Kaytlyn was a Project $\mathrm{O}$ participant) and a written blog with photos (published May 2020, when she had graduated from Project O). ${ }^{4}$ Although both the video and blog were edited by Big hART staff, they provide a personal narrative, generously shared by Kaytlyn. In our discussion, we supplement quotes from Kaytlyn with quotes from other participants, as well as from Project $\mathrm{O}$ staff and mentors.

Drawing on material in the public domain as data means the usual procedural ethics administered by a research ethics committee does not apply. Nevertheless, core ethical principles of respect and fairness still apply. Over the past few years, we have

\footnotetext{
${ }^{4}$ https://projecto.bighart.org/stories and https://www.bighart.org/opportunityandidentity/
} 
had several connections with staff from Big hART and Project O. This has assured us of their support for research and scholarly publication in relation to their work. In addition, our analysis here-while independent and impartial—applies the same strength-based approach to research that Big hART itself applies to its work.

\section{Big hART and Project $O$}

Explicitly strengths-based, Big hART describes itself as 'a Social Change, Arts and Media organisation, delivering non-welfare projects which help counter disadvantage, caused by hidden issues, in isolated communities' ${ }^{5}$ Big hART uses a participatory arts approach to work with communities (in north-west Tasmania as well as elsewhere in Australia) in a way that sits at the intersection of the political dynamics and tensions of 'vulnerability' identified at the start of this paper. Participatory arts practices enabled by Big hART challenge 'singular understandings of the world and strive to reveal the pluralism that permeates everyday contemporary life' (Wright et al. 2016, p1).

Big hART's intention is to create high-quality art with communities and to make 'vulnerable' people's stories visible. ${ }^{6}$ Through participatory community arts practice simplistic categorisations are placed within a broader context, both material and discursive, which constitute the young people's worlds. Big hART's three pillars of work are described in their Annual Report 2019/2020 as thriving communities, safer communities, and connected communities (Big hART 2020a).

The approach of Big hART is driven by projects-one of which is Project O. Project $\mathrm{O}$ aims to engage young women (aged 14-18) to develop skills and learn how to create change in their community, specifically in relation to family violence. Big hART states on its website that:

Project $\mathrm{O}$ is a primary prevention project. Through Project $\mathrm{O}$, young women gain new skills and resilience, equipping them to drive attitudinal change in their community, challenge entrenched gender inequality and help prevent the normalisation of family violence. ${ }^{7}$

Participation in Project $\mathrm{O}$ involves two main types of activities. First, workshops and mentoring are used to build confidence and capabilities. This then sets young women up for the second type of activity: supporting, delivering, and hosting events. In recent years, there have been three major events. Tunes in the Tulips is a collaboration with a tulip farm in north-west Tasmania and involves professional musicians, local produce, and of course an opportunity to admire the tulips in full bloom (Big hART 2020b). The Acoustic Life of Sheds ${ }^{8}$ also involves professional musicians and is part of a major Tasmanian arts festival ' 10 Days on the Island'. These

\footnotetext{
5 https://projecto.bighart.org/about/

${ }^{6}$ https://www.bighart.org/who-we-are/

7 https://projecto.bighart.org/about/

8 https://acousticlifeofsheds.bighart.org/
} 
two events attract large numbers of tourists from around Tasmania and interstate. The third event is the Colourathon, which involves professional visual artists and is a sponsorship-based fundraising drive 'harnessing the global colouring-in mindfulness movement'.

While specific activities have changed over time, they always centre on creative arts as both the hook to draw young women in and the platform for giving participants a voice. In north-west Tasmania, 70 young people participated and were mentored by women artists and arts workers during workshops. In addition young women also had one-on-one mentorships. Artists are paid for their mentoring. While each activity (workshop, event, mentoring) has an inherent structure to it, the overall Project $\mathrm{O}$ is not highly structured, with young women participating in different activities depending on their interest as well as practical considerations such as location and timing.

As their involvement evolved, for young women such as Kaitlyn, their focus shifted from their personal interest to broader issues for young women in their community, including the Project $\mathrm{O}$ genesis as a family violence prevention initiative. Kaytlyn explained in her blog that 'my passion since I was a child has been music' and:

Project $\mathrm{O}$ was offered as a dance and drama group. I didn't know what I was getting myself into. I wasn't aware that I was a victim of this isolated label that's put on our community, and all the issues going on.

Specific to Big hART is that it works through creating art, involving a 'tripartite approach':

(i) a process of enquiry for participants, where issues related to their being in the

world can be inquired into; (ii) a means of upskilling participants in artsspecific skills and knowledge providing them with both specific and general expressive and arts- related skills that are task specific and also transferable, strengthening, for example, creative dispositions and capabilities; and (iii) a form of expression that leads to recognition of aesthetic outcomes, endowing the project and participants with status and recognition. (Wright et al. 2016: 43)

In our analysis below, we connect these three aspects with the proposal by Butler et al. (2016) to think of vulnerability as a precondition for resistance and agency.

\footnotetext{
${ }_{9}$ https://projecto.bighart.org/colourathon/
} 


\section{Resistance: Enquiry into Their Being in the World}

\section{Identity}

A major part of 'their being in the world' and identity for Project $\mathrm{O}$ participants is to do with living in a regional community. Big hART suggests that 'many young people of the North West have felt stigmatised, struggling with isolation and negative perceptions'. ${ }^{10}$ In her blog, Kaytlyn agrees:

The North West Coast is quite a rural area, and isolated in terms of opportunity and platforms to speak openly about issues in the community. I feel some issues are not addressed. ... Project $\mathrm{O}$ gave me a platform which was not there for young women in the community. ... Project $\mathrm{O}$ gave me confidence, but it also made me realise that people put barriers around people from an isolated area that aren't even there. ${ }^{11}$

To some extent, Project $\mathrm{O}$ takes on an awareness-raising role: making vulnerabilities visible for the young women themselves as much as for the wider community. Identification by Project $\mathrm{O}$ of north-west Tasmania as 'a community which struggles with literacy, employment, family violence, poverty, isolation and school retention' ${ }^{12}$ means the organisation treads the sensitive balance between identification in order to provide support where it is most needed and the risk of increased stigmatisation (Te Riele 2015). As Butler (2016: 23) puts it:

We are called names and find ourselves living in a world of categories and descriptions way before we start to sort them critically and endeavour to change or make them on our own. In this way, we are, quite in spite of ourselves, vulnerable to, and affected by, discourses that we never chose.

Project $\mathrm{O}$ uses two specific, practical strategies to avoid stigma. First, activities in Project $\mathrm{O}$ aim to explicitly empower the young women to resist negative stereotypes and take action to reshape perceptions of their region. Such resistance is exemplified by Kaytlyn in her video, where she rails against false boundaries and restrictive expectations:

I was just sitting in my room one day and I am like "you know what I am sick of this "you have to do this with your life", I want to do something different'. People kind of say 'dream big but not too big', they put boundaries in that aren't really there. I want to get past that, I just don't want to do what I am expected to do. ${ }^{13}$

A second strategy to counter stigma and deficit views is taking a strengths-based approach to the region. A Project O staff member talks of "validating the North West

\footnotetext{
10 https://exchange.telstra.com.au/tag/big-hart/

$11 \mathrm{https} / / / \mathrm{www}$.bighart.org/opportunityandidentity/

12 https://exchange.telstra.com.au/tag/big-hart/

13 https://projecto.bighart.org/stories/
} 
Coast of Tasmania as an important place to be, an award-winning place'. ${ }^{14}$ An aim of Project $\mathrm{O}$ is for young women to both 'take pride in themselves and where they live'. ${ }^{15}$ A current Project $\mathrm{O}$ participant Mishca is a budding digital artist. She says:

Growing up on the North West coast has made me really appreciate the beauty and wildness of where we live. I really enjoy being able to drive 15 minutes and end up somewhere that feels so far away from the rest of the world. ${ }^{16}$

Living in a relatively remote corner of Tasmania means, according to a Project O staff member, that the young women 'feel that identity and place are very much entwined'. ${ }^{17}$ For Kaytlyn, an equally important part of her identity is her Aboriginal heritage. Indigeneity is often considered a marker of vulnerability, since Aboriginal and Torres Strait Islander Australians have much poorer experiences on a wide range of education, employment, and health measures (Australian Government 2020). A further complication in Tasmania is the misconception which dominated local views for many decades that Aboriginal Tasmanians were 'extinct'. As a result, Tasmanian Aboriginal people have had to struggle hard to retain connection to their culture and resist dismissal of their identity. This is reflected in Kaytlyn's experience:

Project $\mathrm{O}$ helped me connect in with my Aboriginal identity. I've always felt lost in that area because the Tasmanian history is so hard to flesh out. ... I know who I am. I know that I'm blak but I don't know the full story of my ancestral history. That's really hard for me sometimes - explaining to people. They just want to get a clean answer of my mob and stuff, but you can't always give that as a Tasmanian Aboriginal. ${ }^{18}$

\section{Aspiration}

In addition to their defiant pride in their community and identity-which is so often portrayed in deficit terms - the young women's resistance is evident in their high aspirations. In her video, Kaytlyn takes a stand:

I think people expect us I think as a generation to stick to just what we have always done like stay where we started, like Tasmania for example and not think any bigger, but I want to think bigger, I want to travel the world, I want to sing, I want to meet so many new people and hear their point of view and not just stay in the one place. ${ }^{19}$

Through her participation in Project $\mathrm{O}$, this aspiration became both broader and more practical:

\footnotetext{
${ }^{14}$ https://exchange.telstra.com.au/tag/big-hart/

15 https://exchange.telstra.com.au/tag/big-hart/

16 Note: This data is mandatory. Please provide.

17 https://exchange.telstra.com.au/tag/big-hart/

18 https://www.bighart.org/opportunityandidentity/

19 https://projecto.bighart.org/stories/
} 
I was given a pretty amazing opportunity by the University of Melbourne with a scholarship. It opened my eyes to realise that I could pursue academia. It gives me an opportunity to go anywhere I want in terms of employment after university ... The underlying thing I would like to do is music but it's nice to have that safety net with science, there's so many opportunities under that umbrella. ... Next semester I'm looking at a Diploma of Music. It's concurrent, so I do it at the same time as my science degree, and I get a qualification at the end. I'm still writing music and looking at doing more management and recording. ${ }^{20}$

Comparing Kaytlyn's early aspiration with how she writes about her enrolment in university in her 2020 blog highlights the support needed to enact high aspirations. Based on her research with young women in the same community as where Project $\mathrm{O}$ works, Hawkins (2017) emphasises that cultural and economic capital impact on the capacity to fulfil aspirations. For Kaytlyn, the cultural capital built through Project $\mathrm{O}$ and the economic capital in the form of the university scholarship were essential.

Nevertheless, despite the confidence and pride she displays, Kaytlyn still experiences some insecurity about her background:

I am in a college of 300 other adults who come from everywhere. There's all these people, they're quite well off, and our backgrounds are quite different. When I'm socializing I feel like I'm hiding something, like I'm hiding the fact that I'm not the same. You don't feel you are worth it. That's my biggest challenge - to prove my worth. ${ }^{21}$

Such a sense of having to prove oneself is quite common among university students who are 'first in family' (O'Shea et al. 2017), sometimes feeling like a 'fraud' or 'impostor'. This highlights the importance of resistance in response to vulnerability.

\section{Agency: Upskilling and Status}

\section{Capabilities}

Butler et al. (2016) outline how vulnerability is frequently associated both with victimisation and with paternalism. The resistance to deficit views and assertion of their pride by Project $\mathrm{O}$ participants outlined above forms an outright rejection of being perceived as victims. In this section, we move on to examine the young women's agency-which counters assertions of the need for paternalistic protection by others.

Importantly, assuming that young people have the skills and knowledge required for effective participation and agency simply reinforces the gap between

\footnotetext{
20 https://www.bighart.org/opportunityandidentity/

21 https://www.bighart.org/opportunityandidentity/
} 
marginalised and privileged groups - since the latter are more likely to have home supports for developing those capabilities. Project $\mathrm{O}$ explicitly includes capabilitybuilding activities to empower young women to be "change-makers" ${ }^{\text {, } 2}$ in their community. Kaytlyn explains it as follows:

It developed into more project management, emotional wellbeing, emotional intelligence and how we can impact the community. Later on we started entrepreneurial activities. ... The opportunities that I was given was the biggest asset that I got from Big hART. That was proved when the community started to realise that it was the younger generation of women making change in the community for everyone, not just for us, but for people who were having their lives destroyed by family violence. ${ }^{23}$

Although Project $\mathrm{O}$ has an overall focus on addressing family violence, a staff member argues it 'is not a one-size-fits all program but one that is tailored to each young women's interests and needs, providing them with experiences and opportunities they would not normally have'. ${ }^{24}$ Such tailoring is essential for enabling the young women to pursue the life they themselves value (Sen 1999). Project O engages female mentors whose expertise aligns with participants' interests. Youth mentoring has a long history in Australia, with strong interest in establishing benchmarks and guidelines for high quality mentoring in the early 2000s (e.g. Blaber and Glazebrook 2006). Part of the power of mentoring in Project $\mathrm{O}$ stems from the fact that mentors are not only highly regarded professionals but also (usually) are local. During her time in Project O, Kaytlyn developed her signwriting and performing with Claire-Anne Taylor, a folk musician who grew up in Tasmania's north-west. Kaytlyn writes:

She's been in my life for quite a long time. I look up to her in my personal life but also in terms of music, and where I want to be as a musician. She's definitely my biggest inspiration. ${ }^{25}$

Another local artist, Helene Thomas, worked with Project O participants to develop 'digital podcasting, audio craft and storytelling skills' ${ }^{26}$ in preparation for The Acoustic Life of Sheds. ${ }^{27}$ The mentoring experience was rewarding for Helene as well:

As someone who was born and raised on the North West Coast of Tasmania it was such an honour and privilege to be invited to mentor young women in the art of audio storytelling. These Year 9 and 10 girls have profoundly strong voices with powerful messages. ${ }^{28}$

\footnotetext{
22 https://projecto.bighart.org/about/

23 https://www.bighart.org/opportunityandidentity/

24 https://exchange.telstra.com.au/tag/big-hart/

25 https://www.bighart.org/opportunityandidentity/

26 https://exchange.telstra.com.au/tag/big-hart/

27 https://acousticlifeofsheds.bighart.org/

28 https://exchange.telstra.com.au/tag/big-hart/
} 
A 17-year-old graduate of Project $\mathrm{O}$ who is now herself a mentor comments on 'the support Project $\mathrm{O}$ has in the community', adding that this 'really creates a sense that there's powerful women around you, supporting you' ${ }^{29}$

A highlight of Kaytlyn's mentorship by Claire-Anne Taylor was to write a song together, which Kaytlyn then performed at the Colourathon:

I have been just so lucky to be able to play with Claire-Anne Taylor, it has been amazing and we have been working on a song for the Colourathon and yes it is called 'Moving Mountains' and it is so beautiful. ... It's scary because they all look at you and you have to provide the goods. The song that I played at the end was a song that I wrote myself and it's about what I want to do when I grow up and the sort of things that I will look to pursue. ${ }^{30}$

The Colourathon was delivered and hosted by Project $\mathrm{O}$ participants. True to its ambition to produce high-quality art, ${ }^{31}$ Big hART engaged 'Recognised illustrators and artists [to] create the colouring templates alongside the participants' ${ }^{32}$ By its very nature, however, colouring in is an inclusive artform, building confidence and capacity in young women who may not (yet) see themselves as having artistic skills. Overall, Big hART and Project O seem to match high expectations for the quality of work participants are capable of producing with the support needed for the young women to meet these expectations. Kaytlyn writes: 'Big hART gave me opportunities and a chance to see my worth, and see where I could aim for. I didn't realise I would be able to aim as high as I did'. ${ }^{33}$

The young women experienced success in their art and the events they ran, and gained recognition from artists and from their community.

At Acoustic Life of Sheds, young people were acknowledged and welcomed by the community, made friends with farm owners, spoke to the media, joined in with the crew and cast and were an integral part of the event. They were no longer invisible or on the outer - they were strong, capable and inspiring; they had a voice and we heard their story. ${ }^{34}$

\section{Recognition}

When the wider community recognises young people's efforts and achievements, this helps to counter stigma and enhances agency. A Project O staff member says: 'For any young person to realise that they've been seen, and they've been heard, and their contribution is valued is huge' ${ }^{35}$ Such positive impact is perhaps elevated even further when recognition stems from high-profile artists, as the same Project

\footnotetext{
29 https://exchange.telstra.com.au/tag/big-hart/

30 https://projecto.bighart.org/stories/

31 https://www.bighart.org/who-we-are/

32 https://projecto.bighart.org/colourathon/

33 https://www.bighart.org/opportunityandidentity/

34 https://exchange.telstra.com.au/tag/big-hart/

35 https://exchange.telstra.com.au/tag/big-hart/
} 
O staff member suggests: 'The most important thing I think for the young women is the realisation that they are heard and valued by noted artists in the industry, ${ }^{36}$ For example, Helene Thomas (an artist-mentor mentioned above) commented on the quality of the audio story of one of the young women: 'Trinity took me to her special place, spoke about why she liked to go there and how it made her feel. She captured sounds of the water and birdlife so beautifully'. ${ }^{37}$ Further, public recognition came when the stories by Trinity and other participants were then incorporated as 'an immersive audio experience' into the performance for The Acoustic Life of Sheds by Tasmanian percussionist Maggie Abraham. ${ }^{38}$

The first Colourathon in 2016 earned Project O the 'Community Event of the Year Australia Day award' from their local council. This added to the recognition young women had already experienced during the event itself, though the sponsorship and support from local businesses. In their speech at the award ceremony, the young women said:

Every hour that we coloured-in we were sponsored AND supported by our community ... These relationships are important to us, they tell us that we are not alone, they send the message that even though we are young, our voices are important. ${ }^{39}$

More recently, during the COVID-19 pandemic, young women worked to create 'digital works of film, animation, illustrations, poetry and TikToks' in collaboration with artists which 'saw their work stretched further and reflected back to them'. In the process, a Project $\mathrm{O}$ staff says:

The outside artists also validate the young women, echoing what we've been telling them this whole time - that they're strong, growing, fantastic women who have the power to do exactly what they want to do. ${ }^{40}$

Although this kind of validation can be perceived as the paternalism Butler et al. (2016) are so wary of, external recognition is important for Project O participants. Many of the achievements of Project $\mathrm{O}$ participants are impressive. Through Tunes in the Tulips, they 'engage with tourism industry skills and agriculture [and in] drone piloting and filming, science communication, tourism marketing and graphic design'(Big hART 2020b). With Colourathon, they raised funding to address family violence, with participants writing:

It was a good thing for us to do, it will definitely make a difference, and the community doesn't see us as 'school kids that can't do anything' anymore.

\footnotetext{
36 https://exchange.telstra.com.au/tag/big-hart/

37 https://exchange.telstra.com.au/tag/big-hart/

38 https://www.bighart.org/wp-content/uploads/2017/05/AcousticLifeofSheds-2019_PressRelease.pdf

39 https://projecto.bighart.org/feeling-like-award-specialists-waratah-wynyard-australia-day-awards2017/

${ }^{40}$ https://exchange.telstra.com.au/tag/big-hart/
} 
We actually did something. We hosted an event. We all helped each other and stepped up and raised so much more than we ever thought possible. ${ }^{41}$

For The Acoustic Life of Sheds, they had responsibility ranging 'from promotion to front-of-house, media and assisting with technical stage and sound production' (Big hART 2019). Such achievements engender a sense of pride in the young women, further demonstrating their strengths and enhancing their agency to push back against preconceived notions of their vulnerability. As a graduate from Project O, Kaytlyn was involved in The Acoustic Life of Sheds and reflects:

I really loved the Acoustic Life of Sheds. You had artists coming together, but also the next generation of Project $\mathrm{O}$ girls coming through. It was so cool to look at those girls, having known them from quite a young age. Seeing them step into my shoes and get their hands on those opportunities. It was quite empowering to see that happen. ${ }^{42}$

Through Project O, young people's human right to equal participation in society is advanced, putting in practice Articles 12 and 13 of the United Nations Convention on the Rights of the Child (UNCRC). In the child-friendly version (UNICEF n.d.: 3), these articles state:

12 Children have the right to give their opinions freely on issues that affect them. Adults should listen and take children seriously. 13 Children have the right to share freely with others what they learn, think and feel, by talking, drawing, writing or in any other way unless it harms other people.

By combining a rights-based perspective with a strengths-based approach, Project $\mathrm{O}$ overcomes the concerns of Butler et al. (2016: 5-6) that human rights frameworks can lead to 'foreclosing or devaluing modes of collective resistance among those designated as vulnerable'. In her advice to other young people in north-west Tasmania, Kaytlyn writes:

Try everything that you can, because you never know where it'll take you. Project $\mathrm{O}$ is the biggest example of that $-\mathrm{I}$ thought I was going to a dance class and I came out having raised over $\$ 12,000$ for family violence.

\section{Conclusions}

In this paper, we have shown how structures of social, economic, and cultural inequalities provide the context for the vulnerability of young women in Tasmania's north-west, as well as how a strengths-based approach can build capabilities that empower these young women to not only lead their own life in the way they value (Sen 1999) but also to be change-makers for their community. Butler et al. (2016: 2) argue: 'there is always something both risky and true in claiming that women or

${ }^{41}$ https://projecto.bighart.org/24-hour-colourathon/

42 https://www.bighart.org/opportunityandidentity/ 
other socially disadvantaged groups are especially vulnerable'. They go on to offer hope that there are:

... initiatives that, while refusing these forms of politics that amount to the stigmatization and the further disempowerment of the women they are said to protect or save, do not dismiss the induced vulnerability to which many women are exposed and try to offer alternative resources for self-empowerment, collective agency, and protection. (Butler et al. 2016: 2)

We suggest that Project $\mathrm{O}$ is such an initiative. This is evident in the language explicitly used, that Project $O$ supports young women 'to be leaders - capable of driving change', using 'an asset-based, non-welfare approach, building on the strengths of communities, and backing the potential of the young women who live there'. 43

At the start of this paper, we outlined tensions in identifying some young people as vulnerable. Opposition to the concept of vulnerability may, Butler et al. (2016: 6) suggest, be because 'vulnerability has not been adequately related to the existing practices of resistance'. Project $\mathrm{O}$ is an example of a practical way to overcome such tensions and harness the potential of vulnerability as a starting point for both resistance and agency, through positive connections with place and identity; by enabling young women to act on their aspirations; and by developing capabilities and providing recognition.

Butler (2016: 14-15) emphasises that 'No one moves without a supportive environment and set of technologies'. Project $\mathrm{O}$ illustrates the kinds of support that can enable young women to move, individually and collectively. In a major report, Wright et al. (2016: 98-99) argue in relation to Big hART (including Project O) that:

... agency is contingent on opportunity, learning, resources, culture and social equality ... the social imaginary [Big hART] employed strengthened agency. What this meant was that difference became an asset rather than a deficit, thereby adding value to young people's lives though what they both lived and embodied. In this sense, BIG hART developed agency as capacity-in-action.

It is only right for us to leave the last word to Kaytlyn, with the lyrics to her song 'I am going to move mountains', as sung in her video ${ }^{44}$ :

We didn't know it then

back when it all began

that one day we would stand as sisters hand in hand

so we took our fears and our doubts and we threw them out

and when they try to creep in that's when we start singing, even if I fall

I pick myself up

and stand proud and tall even in a storm.

\footnotetext{
43 https://projecto.bighart.org/about/

44 https://projecto.bighart.org/stories/
} 


\section{Declarations}

Conflict of Interest The authors declare that there is no conflict of interest.

\section{References}

AIHW (2019) Family, domestic and sexual violence in Australia: continuing the national story. Australian Institute of Health and Welfare, Canberra

Androutsopoulos J (2008) Potentials and limitations of discourse-centred online ethnography. Language@ internet, 5(8) (online) https://www.languageatinternet.org/articles/2008/1610/androutsop oulos.pdf

Arora SK, Li Y, Youtie J, Shapira P (2016) Using the wayback machine to mine websites in the social sciences: a methodological resource. J Am Soc Inf Sci 67(8):1904-1915

Australian Bureau of Statistics (2016) Census of population and housing. https://www.abs.gov.au/websi tedbs/censushome.nsf/home/2016

Australian Government (2020) Closing the Gap. https://www.closingthegap.gov.au/

Big hART (2019) Acoustic Life of Sheds Press Release https:/www.bighart.org/wp-content/uploads/ 2017/05/AcousticLifeofSheds-2019_PressRelease.pdf

Big hART (2020a) Annual Report 2019-2020. https://www.bighart.org/wp-content/uploads/2020/11/ 2019-2020-Big-hART-Annual-Report_LowRes_FINAL.pdf

Big hART (2020b) Tunes in the tulips. https:/www.bighart.org/wp-content/uploads/2017/04/Tunes-inthe-Tulips-MR-2020.pdf

Blaber D, Glazebrook D (2006) A guide to effective practice for mentoring young people. Department for Victorian Communities, Melbourne

Butler J (2016) Rethinking vulnerability and resistance. In: Butler J, Gambetti Z, Sabsay L (eds) Vulnerability in resistance. Duke University Press, Durham, pp 12-27

Butler J, Gambetti Z, Sabsay L (2016) Introduction. In: Butler J, Gambetti Z, Sabsay L (eds) Vulnerability in resistance. Duke University Press, Durham, pp 1-11

Creswell J, Poth C (2017) Qualitative inquiry and research design: choosing among five approaches, 4th edn. Sage, London

Cuervo H, Wyn J (2012) Young people making it work: continuity and change in rural places. Melbourne University Publishing, Melbourne

Denny L, Pisanu N (2019) Insight Nine: Regional population trends in Tasmania: issues and Options. Institute for the Study of Social Change, University of Tasmania, Hobart

Denny L, Shelley B, Ooi CS (2019) Education, jobs and the political economy of tourism: Expectations and realities in the case of Tasmania. Australas J Reg Stud 25(2):282

Department of Education Tasmania (2020) Education Act. https://www.education.tas.gov.au/about-us/ legislation/education-act/. Accessed $20 \mathrm{Jul} 2021$

Eslake S (2020) Tasmania Report 2020. http://www.tcci.com.au/Services/Policies-Research/TasmaniaRe port. Accessed 20 Jul 2021

Hardy A, Ooi CS (2020) Tasmania: The state of the state. In: Ooi CS, Hardy A (eds) Tourism in Tasmania. Hobart, Forty South, pp 1-6

Hawkins C (2017) Do aspirations really matter? Aust Int J Rural Educ 27(3):39-54

Hine C (2000) Virtual ethnography. Sage, London

Katz M (2013) The undeserving poor: America's enduring confrontation with poverty: fully updated and revised, 2nd edn. Oxford University Press, New York

Lamb S, Huo S, Walstab A, Wade A, Maire Q, Doecke E, Jackson J, Endekov Z (2020) Educational opportunity in Australia 2020: Who succeeds and who misses out. Victoria University, Melbourne

Medhora S, Evershed N (2015) Six out of 12 new domestic violence hubs will be in regional Australia. The Guardian (28 Sep)

O’Shea S, May J, Stone C, Delahunty J (2017) First-in-family students, university experience and family life: Motivations, transitions and participation. Palgrave Macmillan, London

Sen A (1999) Development as freedom. Oxford University Press, Oxford 
Te Riele K (2015) Conundrums for Youth Policy and Practice. In: te Riele K, Gorur R, R. (eds) Interrogating conceptions of "vulnerable youth" in theory, policy and practice. Rotterdam, Sense, pp 17-32

Thomas J, Barraket J, Wilson CK, Holcombe-James I, Kennedy J, Rennie E, Ewing S, MacDonald T (2020) Measuring Australia's digital divide: the Australian Digital Inclusion Index. RMIT and Swinburne University of Technology, for Telstra, Melbourne

UNICEF (n.d.) Convention on the Rights of the Child - child-friendly version. https://www.unicef.org/ media/56661/file. Accessed 20 Jul 2021

Waters J, Brooks R (2015) 'The magical operations of separation': English elite schools' on-line geographies, internationalisation and functional isolation. Geoforum 58:86-94

Wierenga A (2009) Young people making a life. Palgrave Macmillan, London

Wright P, Down B, Rankin S, Haseman B, White M, Davies C (2016) BIG hART: Art, equity and community for people, place and policy. Murdoch University, Rockingham

Publisher's note Springer Nature remains neutral with regard to jurisdictional claims in published maps and institutional affiliations. 